doi: $10.2306 /$ scienceasia1513-1874.2012.38.289

\title{
Mechanical and thermal properties of oil palm wood sawdust reinforced post-consumer polyethylene composites
}

\author{
Thanate Ratanawilai*, Natchayapa Thanawattanasirikul, Chatree Homkhiew \\ Department of Industrial Engineering, Faculty of Engineering, Prince of Songkla University, Hat Yai, \\ Songkhla 90112 Thailand \\ *Corresponding author, e-mail: thanate.r@psu.ac.th
}

Received 28 Mar 2012

Accepted 29 Aug 2012

\begin{abstract}
Post-consumer recycled high-density polyethylene (PCR-HDPE) composites reinforced with 30, 40, and $50 \%$ of oil palm wood sawdust (OWS) were prepared by compression moulding. The effects of the OWS content and the moulding temperature on the flexural and compressive properties of the composites were investigated and were found to be highly significant. Increases in the proportion of OWS in the matrix caused a gradual worsening in the mechanical properties of the composites. However, higher moulding temperatures moderately improved the mechanical properties. Dynamic mechanical thermal analysis was used to study the viscoelastic behaviour, and thermogravimetric analysis was used to study the thermal stability of the composites. The storage and loss moduli gradually decreased with increasing temperature and significantly increased with increasing the proportion of OWS in the composites. The thermal stability of the composites slightly dropped with a higher OWS content. These results suggest that PCR-HDPE and OWS can be used to create composite materials with good mechanical and thermal properties.
\end{abstract}

KEYWORDS: hot-pressed mould, flexural strength, compressive strength, thermal stability

\section{INTRODUCTION}

The global production of plastics has increased from approximately 1.5 million tonnes in 1950 to reach 245 million tonnes in $2008^{1}$, resulting in a significant contribution to municipal solid waste (MSW). For example, the US generated at least 33.6 million tons of post-consumer plastics in 2008, of which 28.9 million tons (85.8\% of total plastics in MSW) were landfilled, 2.6 million tons $(7.7 \%)$ were combusted with energy recovery, and 2.2 million tons $(6.5 \%)$ were recycled ${ }^{2}$. This suggests that the percentage reuse of plastic waste is minimal. Therefore, attempting to increase the value of plastic waste, for instance, by blending post-consumer plastics with wood flour could be important. The use of recycled plastics would not only decrease the consumption of natural resources and energy but also provide an effective and safe means of disposing of plastic waste ${ }^{3}$. A small number of studies have reported the use of recycled plastics in a matrix of wood-plastic composites (WPCs). For example, the feasibility of using recycled high density polyethylene, polypropylene, and old newspaper fibre to manufacture composite panels was investigated and found that recycled materials can be used to manu- facture value-added panels without diminishing board properties. Wood/recycled plastic composite materials were fabricated successfully by mixing recycled HDPE and post-consumer wood sawdust from a single screw extruder ${ }^{4}$. Recycled expanded polystyrene and wood flour can be used to manufacture composites with high mechanical properties and low density ${ }^{5}$. Furthermore, composites made from post-consumer recycled HDPE (PCR-HDPE) have similar or, in some cases, better mechanical properties than composites made from virgin $\mathrm{HDPE}^{6,7}$. Natural organic flours obtained from renewable natural resources are inexpensive fillers which are generated during different stages of wood processing such as at sawmills and in furniture making ${ }^{8}$. These wood flours have the potential to be used as biodegradable reinforcing materials because of their acceptable specific strength and modulus, low cost, low density, biodegradability, easy fibre surface modification, good thermal insulation, the absence of associated health hazards, and the fact that they are renewable resources ${ }^{9}$. Natural wood flours, such as those derived from rubberwood, pine, maple, and oak have been successfully used to improve the mechanical and thermal properties of wood-plastic composites and to reduce their costs ${ }^{10}$. 
However, there has been only limited work done on blends of oil palm wood sawdust and recycled plastic composites. Increasing the use of recycled plastics and waste wood products by turning them into low cost wood-plastic composites holds out the prospect of reducing solid waste disposal. Recycled plastics are generally thermoplastics such as high density polyethylene (HDPE), and their properties are gradually decreased when they are heated. Thus the aim of this study was to explore composites made from waste oil palm wood sawdust and PCR-HDPE and to investigate the effect of the wood sawdust content and the moulding temperature on the mechanical and thermal properties and microstructure of oil palm wood sawdust reinforced PCR-HDPE.

\section{MATERIALS AND METHODS}

\section{Materials}

Oil palm (Elaeis guineensis Jacq.) wood sawdust, from more than 25 years old trees, was collected from a local sawmill. The main chemical constituents are: cellulose $(29.2 \%)$, pentosan (18.8\%), lignin (18.8\%), hemicellulose (16.5\%), and ash (2\%). The sawdust was sieved through a standard sieve of 30-70 mesh size and was dried in an oven at $105^{\circ} \mathrm{C}$ for $5 \mathrm{~h}$ before compounding. Recycled HDPE (rHDPE) was procured from a local plastic recycling factory, and originated mainly from the post-consumer recycling of water bottles. The plastic water bottles were thoroughly ground in a plastic grinder and then washed with water. After being oven-dried overnight at $100{ }^{\circ} \mathrm{C}$, the granules were sieved through a standard sieve of 40-140 mesh size. Maleic anhydride (MA; Fluka 63210 , purum, $\geqslant 98 \%$ NT) was added as a coupling agent.

\section{Preparation of composites}

The mass ratios of biofibres to polymer and coupling agent used to prepare different samples are listed in Table 1. The recycled HDPE was dry-blended with sawdust particles and maleic anhydride using a highspeed mixer for $5 \mathrm{~min}$. The mixtures were then moulded in a compression moulding machine (Lin Cheng Technologies, LCC 140, Taiwan) and samples of each formulation were heated to 130,150 , or $170^{\circ} \mathrm{C}$ before being placed on the bottom platen of a mould. The mixtures were then hot-pressed for $50 \mathrm{~min}$ under a pressure of $2500 \mathrm{psi}$. The panel thickness was controlled by using $20 \mathrm{~mm}$ spacers. The final composite panel size was $60 \mathrm{~mm} \times 300 \mathrm{~mm}$ with a thickness of $20 \mathrm{~mm}$. Subsequently, the panels were machined to conform to ASTM for each test.
Table 1 Composition of wood-plastic composites.

\begin{tabular}{lccc}
\hline Code & OWS (wt\%) & rHDPE (wt\%) & MA (wt\%) \\
\hline A & 30 & 67 & 3 \\
B & 40 & 57 & 3 \\
C & 50 & 47 & 3 \\
\hline
\end{tabular}

\section{Characterization}

Mechanical tests: The compression and flexural properties of the composites were measured using an Instron Universal Testing Machine (Model 5582, USA). Compression tests were conducted according to ASTM D 6108 at a testing speed of $5 \mathrm{~mm} / \mathrm{min}$. For the flexural properties, three-point flexural tests were performed in accordance with ASTM D 6109. The tests were conducted at a cross-head speed of $2 \mathrm{~mm} / \mathrm{min}$. All the mechanical tests were carried out at room temperature $\left(25^{\circ} \mathrm{C}\right)$ with five replications. The average results and their standard deviations were recorded.

Dynamic mechanical thermal analysis: Dynamic mechanical thermal analysis (Rheometric scientific DMTA V, USA) was also performed to measure storage $\left(E^{\prime}\right)$ and loss $\left(E^{\prime \prime}\right)$ modulus. The measurements were carried out in a dual cantilever bending using rectangular specimens of dimensions $10 \mathrm{~mm} \times 35 \mathrm{~mm} \times 3 \mathrm{~mm}$. The test was dynamic with a temperature range of $25-200{ }^{\circ} \mathrm{C}$ at a heating rate of $3{ }^{\circ} \mathrm{C} / \mathrm{min}$ and strain amplitude of $0.1 \%$. A load frequency of $10 \mathrm{~Hz}$ was used.

Thermogravimetric analysis (TGA): A Perkin Elmer (TGA-7, USA) thermal analyser was used for TGA and to establish the thermal stability of the composites. Approximately 5-6 mg samples were scanned from $50-1000^{\circ} \mathrm{C}$ under nitrogen atmosphere at a heating rate of $10^{\circ} \mathrm{C} / \mathrm{min}$. The onset temperature was determined from the TGA curve.

Scanning electron microscopy: The state of dispersion, interface adhesion, and voids in the wood flour in the polymeric matrix were analysed with a scanning electron microscope (SEM). An FEI Quanta 400 microscope (USA) working at $15 \mathrm{kV}$ was used to obtain microphotographs of the surface of the composites.

\section{RESULTS AND DISCUSSION}

\section{Flexural and compressive properties}

The flexural and compressive strengths of the WPCs containing different amounts of OWS are shown in Fig. 1 and Fig. 2, respectively. The flexural and compressive strengths gradually decreased with increased 


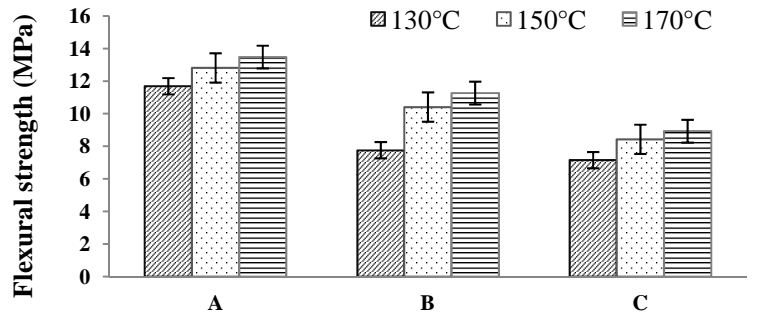

Fig. 1 Flexural strength of WPCs at different moulding temperature.

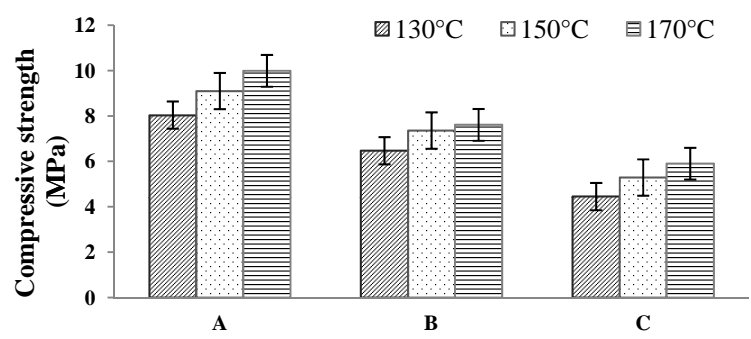

Fig. 2 Compressive strength of WPCs at different moulding temperature.

proportions of OWS in the matrix. These decreases are a result of the system being immiscible causing poor dispersion and adhesion of the wood particles in the matrix, and the findings are in good agreement with Ref. 11. From the SEM micrographs shown in Fig. 3, it can be observed that when the OWS concentration was increased, the matrix coverage was insufficient and many voids appeared leading to weak interfacial adhesion. Any initial separation spreads easily ${ }^{12}$, and thus reduces the mechanical strength of the composites. In addition, the many voids or cavities in the structure of oil palm wood are another significant factor in the reduction of mechanical properties.

Further, the different moulding temperatures significantly affected the mechanical properties. For all formulations, the flexural and compressive strengths gradually increased with increasing temperature. These increases are due to the melting of the polymer matrix in the composites, and could be explained as the higher degree of melting of the polymer enabling it to have more mobility by the polymer segment chains and so the matrix may involve better the fibre, resulting in good adhesion between the (hydrophilic) sawdust and the (hydrophobic) polymer matrix.

\section{Morphological structure of the composites}

The interaction of the OWS filler and its compatibility and dispersion in the PCR-HDPE matrix was studied using an SEM. The morphology of the composites
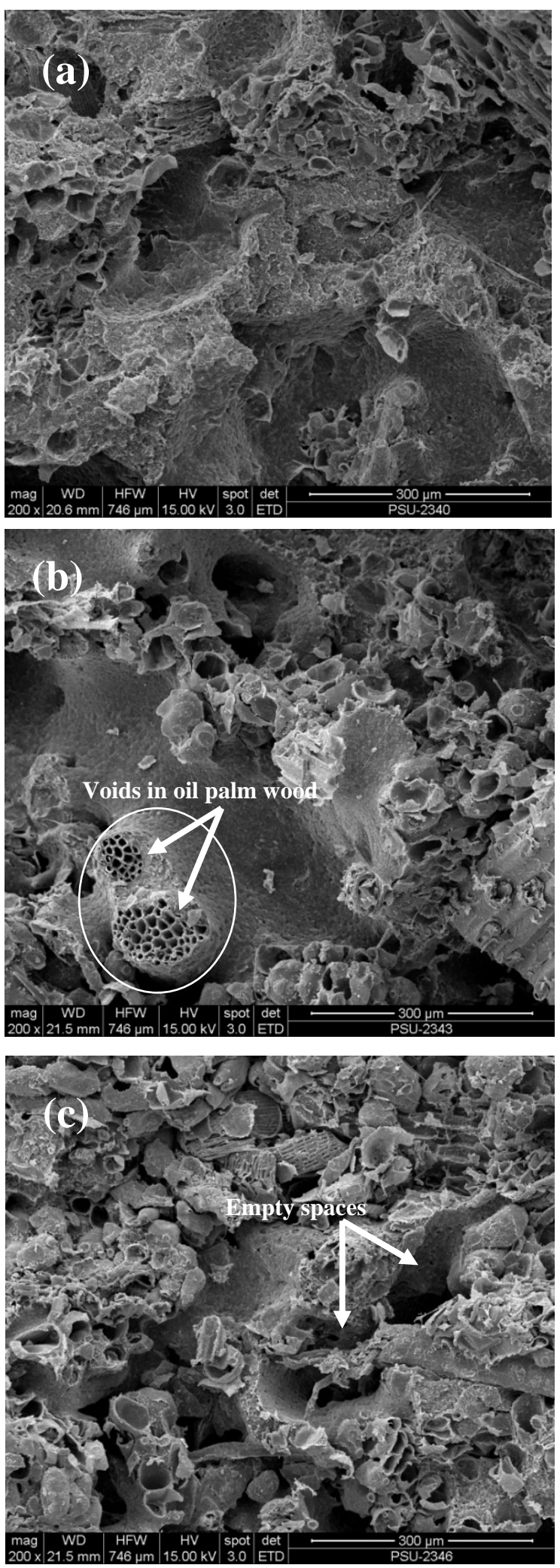

Fig. 3 SEM micrographs of PCR-HDPE composites containing (a) 30, (b) 40, and (c) $50 \mathrm{wt} \%$ of OWS. 
revealed poor interfacial adhesion and dispersion between the OWS and the polymer matrix (Fig. 3). From Fig. $3 b$ and $c$, it is evident that the matrix surface in the composites included a large number of empty spaces and agglomerations of sawdust ${ }^{13}$. This result is due to the presence of lignin and the $\mathrm{OH}$ groups on the cellulose, which bind the sawdust to form agglomerations ${ }^{14}$. Further, increasing the OWS content weakens the interfacial adhesion and increases the number of voids because of the difficulty of dispersing the OWS particles and their propensity to strong agglomeration. This leads to a reduction in the mechanical properties of the composites.

\section{Dynamic mechanical thermal properties}

The temperature dependence of the dynamic storage modulus $\left(E^{\prime}\right)$ and the loss factor $\left(\tan \delta=E^{\prime \prime} / E^{\prime}\right)$ for composites with $30 \mathrm{wt} \%, 40 \mathrm{wt} \%$, and $50 \mathrm{wt} \%$ of OWS is shown in Fig. 4. In all formulations, the storage modulus gradually decreased with increasing temperature and then suddenly dropped as the material became sufficiently soft ${ }^{15}$. The storage modulus significantly increased with higher proportions of OWS to PCR-HDPE. This may be because of the increase in the stiffness of the matrix caused by the reinforcement effect imparted by the OWS, because wood sawdust is more rigid than the polymer matrix ${ }^{16}$. Above $150^{\circ} \mathrm{C}$ for all formulations, the storage modulus suddenly decreased due to the phenomenon widely known as melting temperature. This behaviour shows that the melting temperature of WPCs is independent of the proportion of sawdust filler in the mixture. Additionally, the difference in the $\tan \delta$ values between sawdust loading at low temperature is only marginal. At higher temperatures $\left(>160^{\circ} \mathrm{C}\right)$, however, this difference is more predominant ${ }^{17}$. The $\tan \delta$ values for all the OWS and PCR-HDPE composites increased with increasing temperature, but the increasing OWS content decreased the $\tan \delta$ values at higher temperatures. The result is in good agreement with previous work $^{18}$. The addition of wood flour reduces the $\tan \delta$ peak height by restricting the movement capacity of the polymer chains. In the polymers, the molecule chain segments are independent from restraints ${ }^{19}$.

The loss modulus $\left(E^{\prime \prime}\right)$ showed similar trends to the storage modulus. The $E^{\prime \prime}$ values of the OWS and PCR-HDPE composites are illustrated in Fig. 5. It is evident that with the admixture of wood sawdust into the PCR-HDPE matrix, the loss modulus increased with the proportion of OWS. This phenomenon is due to the higher OWS content increasing the internal friction which enhances the dissipation of energy in the composite ${ }^{5,20}$. Additionally, the loss modulus

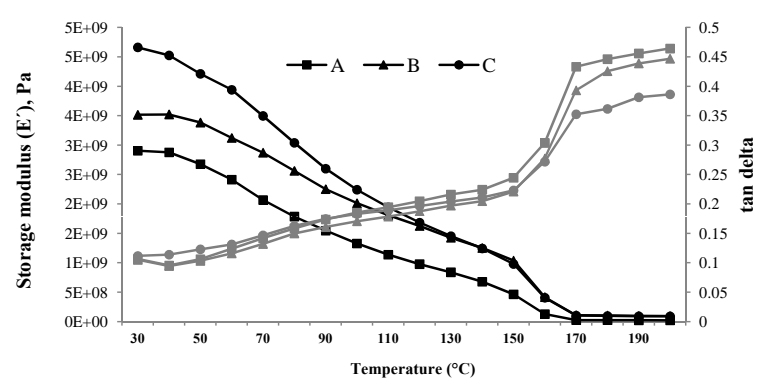

Fig. 4 Temperature dependence of storage modulus and loss tangent for composites filled with 30,40 , and $50 \mathrm{wt} \%$ of OWS.

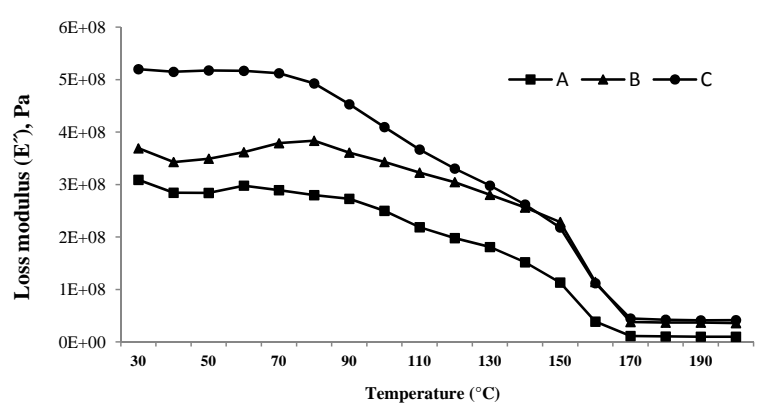

Fig. 5 Variation in loss modulus with temperature for composites filled with 30, 40, and $50 \mathrm{wt} \%$ of OWS.

value was noted to be higher due to the presence of OWS which reduced the flexibility of the composite material by introducing constraints on the segmental mobility of the polymeric molecules at the relaxation temperatures ${ }^{5,20-22}$.

\section{Thermal stability}

Thermogravimetric analysis involves measurement of the weight loss or gain of a material as a function of time and temperature ${ }^{23}$, and it has proved to be an effective method for evaluating the thermal stability of polymers ${ }^{24,25}$. The TGA and derivative thermogravimetric (DTG) curves of PCR-HDPE composites containing $30 \mathrm{wt} \%, 40 \mathrm{wt} \%$, and $50 \mathrm{wt} \%$ of OWS are shown in Fig. 6 and Fig. 7, respectively. The thermal stability was markedly reduced with increasing OWS content. Fig. 7 shows that the decomposition profiles of the OWS and PCR-HDPE composites are characterized by two peaks. The first one, which corresponded to the degradation (TGA) of wood components (e.g., hemicelluloses, cellulose, lignin), started at about 249,231 , and $195^{\circ} \mathrm{C}$ with maximum weight loss rates (DTG) at 364,360 , and $361^{\circ} \mathrm{C}$ for the composites with $30 \mathrm{wt} \%, 40 \mathrm{wt} \%$, and $50 \mathrm{wt} \%$ of OWS, respectively. The cellulose, hemicelluloses 


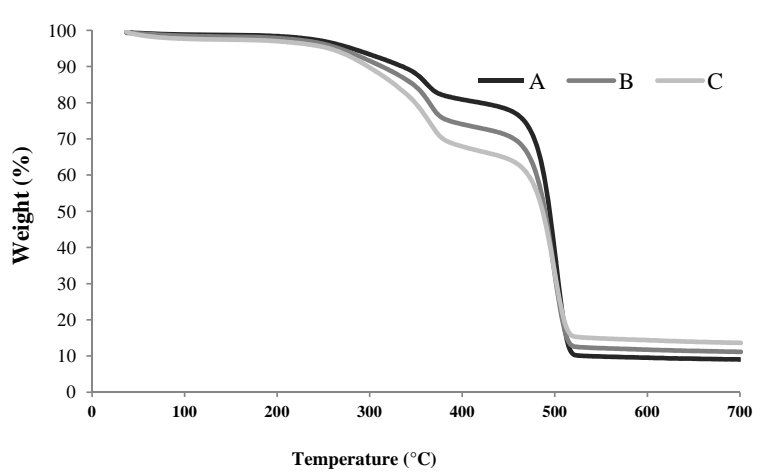

Fig. 6 TGA curves of PCR-HDPE composites containing 30,40 , and $50 \mathrm{wt} \%$ of OWS.

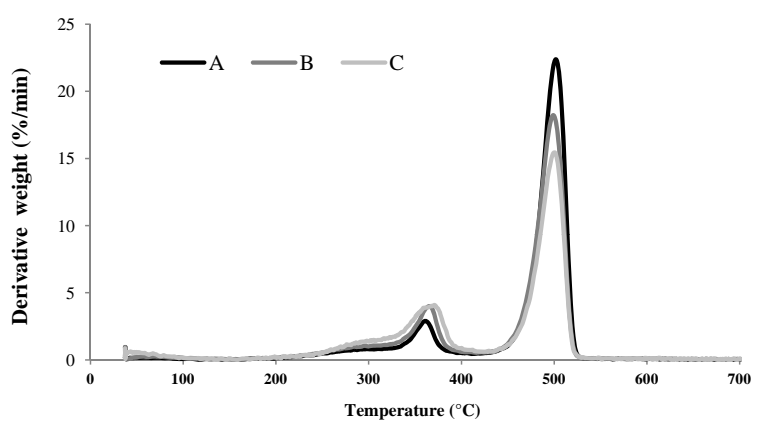

Fig. 7 DTG curves of PCR-HDPE composites containing 30,40 , and $50 \mathrm{wt} \%$ of OWS.

component of the natural filler in the composites degraded in the temperature range $274-459^{\circ} \mathrm{C}^{24}$. In the second step, PCR-HDPE degradation (TGA) occurred between 450,442 , and $440{ }^{\circ} \mathrm{C}$ with DTG at 501, 500 , and $500{ }^{\circ} \mathrm{C}$ for composites containing $30 \mathrm{wt} \%$, $40 \mathrm{wt} \%$, and $50 \mathrm{wt} \%$ of OWS, respectively. This phenomenon has also been reported for other polymers reinforced with lignocellulosic fibres ${ }^{24,26}$.

The TGA data relates to the temperatures corresponding to initial weight loss. From Table 2, it can be observed that the percentage weight decreased with increases in both the OWS content and the temperature. Higher values of this percentage weight indicate higher thermal stability of the composites ${ }^{24,27}$. This result was probably due to more degradation of OWS than PCR-HDPE occurring, and the poor interfacial adhesion between the OWS and the polymer matrix. This is in good agreement with Ref. 21. An increase in interfacial adhesion between the fibres and the matrix increased the thermal stability and decreased the percentage of weight loss. This result indicates a significant effect on the thermal stability of the composites after incorporating OWS filler.
Table 2 Weight percentage of OWS/PCR-HDPE composites at different temperatures.

\begin{tabular}{lccc}
\hline Temperature $\left({ }^{\circ} \mathrm{C}\right)$ & \multicolumn{3}{c}{ Weight $(\%)$} \\
\cline { 2 - 4 } & $\mathrm{A}$ & $\mathrm{B}$ & $\mathrm{C}$ \\
\hline 100 & 98.8 & 98.4 & 97.7 \\
200 & 98.4 & 97.8 & 96.9 \\
300 & 93.4 & 91.5 & 89.2 \\
400 & 80.9 & 74.0 & 67.7 \\
500 & 38.8 & 36.2 & 34.5 \\
600 & 9.6 & 11.8 & 14.4 \\
\hline
\end{tabular}

\section{CONCLUSIONS}

In this study, moulded composites were produced from PCR-HDPE and OWS. The effects of the proportion of OWS and moulding temperatures on the flexural and compressive strengths were highly significant. The composites with lower OWS content and those subjected to higher moulding temperature showed superior mechanical properties. However, the morphology of the composites with a higher OWS content demonstrated poor interfacial adhesion and dispersion between the OWS and the polymer matrix. Moreover, increasing the proportion of OWS significantly increased the storage and loss modulus, whereas the $\tan \delta$ values decreased at higher temperatures. The storage and loss modulus gradually decreased with increasing temperature and then suddenly dropped at $150^{\circ} \mathrm{C}$, the melting temperature. The TGA and DTG data showed that the decomposition of the composites occurred at two peaks, corresponding to the temperatures at which the OWS and PCRHDPE degraded, and thermal stability was observed to decrease with a higher proportion of OWS in the polymer matrix.

Acknowledgements: The authors gratefully acknowledge the financial support from the graduate school of Prince of Songkla University and Rubberwood Technology and Management Research Group (ENG-54-27-11-0137-S) of Faculty of Engineering, Prince of Songkla University, Thailand.

\section{REFERENCES}

1. Plastics Europe (2009) The compelling facts about plastics 2009 an analysis of European plastic production, demand and recovery for 2008 Brussels: Association of Plastics Manufacturers, Belgium.

2. Themelis NJ, Castaldi MJ, Bhatti J, Arsova L (2011) Energy and economic value of nonrecycled plastics (NRP) and municipal solid wastes (MSW) that are currently landfilled in the fifty States. EEC Study of Non- 
Recycled Plastics. Earth Engineering Center, Columbia Univ.

3. Khan ZA, Kamaruddin S, Siddiquee AN (2010) Feasibility study of use of recycled high density polyethylene and multi response optimization of injection moulding parameters using combined grey relational and principal component analyses. Mater Des 31, 2925-31.

4. Cui Y, Lee S, Noruziaan B, Cheung M, Tao J (2008) Fabrication and interfacial modification of wood/recycled plastic composite materials. Compos Appl Sci Manuf 39, 655-61.

5. Poletto M, Dettenborn J, Zeni M, Zattera AJ (2011) Characterization of composites based on expanded polystyrene wastes and wood flour. Waste Manag 31, 779-84.

6. Adhikary KB, Pang S, Staiger MP (2008) Dimensional stability and mechanical behaviour of wood-plastic composites based recycled and virgin high-density polyethylene (HDPE). Compos B Eng 39, 807-15.

7. Selke SE, Wichman I (2004) Wood fiber/polyolefin composites. Compos Appl Sci Manuf 35, 321-6.

8. Ashori A, Sheshmani S (2010) Hybrid composites made from recycled materials: moisture absorption and thickness swelling behavior. Bioresour Tech 101, 4717-20.

9. Lei Y, Wu Q, Yao F, Xu Y (2007) Preparation and properties of recycled HDPE/natural fiber composites. Compos Appl Sci Manuf 38, 1664-74.

10. Favaro SL, Lopes MS, Neto AGVC, Santana RR, Radovanovic E (2010) Chemical, morphological, and mechanical analysis of rice husk/post-consumer polyethylene composites. Compos Appl Sci Manuf 41, 154-60.

11. Sombatsompop N, Chaochanchaikul K, Phromchirasuk C, Thongsang S (2003) Effect of wood sawdust content on rheological and structural changes, and thermomechanical properties of $\mathrm{PVC} / \mathrm{sawdust}$ composites. Polymer Int 52, 1847-55.

12. Ndiaye D, Matuana LM, Therias SM, Vidal L, Tidjani A, Gardette JL (2011) Thermal and mechanical properties of polypropylene/wood-flour composites. J Appl Polymer Sci 119, 3321-8.

13. Li B, Jiang H, Guo L, Shi H (2008) Comparative study on the effect of manchurian ash and larch wood flour on mechanical property, morphology, and rheology of HDPE/wood flour composites. J Appl Polymer Sci 107, 2520-30.

14. Ge XC, Li XH, Meng YZ (2004) Tensile properties, morphology, and thermal behavior of PVC composites containing pine flour and bamboo flour. J Appl Polymer Sci 93, 1804-11.

15. Thongruang W, Balik CM, Spontak RJ (2002) Volumeexclusion effects in polyethylene blends filled with carbon black, graphite, or carbon fiber. J Polymer Sci B Polymer Phys 40, 1013-23.

16. Prachayawarakorn J, Khamsri J, Chaochanchaikul K,
Sombatsompop N (2006) Effects of compatibilizer type and rubber-wood sawdust content on the mechanical, morphological, and thermal properties of PVC/LDPE blend. J Appl Polymer Sci 102, 598-606.

17. Joseph PV, Mathew G, Joseph K, Groeninckx G, Thomas S (2003) Dynamic mechanical properties of short sisal fibre reinforced polypropylene composite. Compos Appl Sci Manuf 34, 275-90.

18. Jiang H, Kamdem DP (2008) Thermal and dynamic mechanical behavior of poly(vinyl chloride)/wood flour composites. J Appl Polymer Sci 107, 951-7.

19. Pothan LA, Oommen Z, Thomas S (2003) Dynamic mechanical analysis of banana fiber reinforced polyester composites. Compos Sci Tech 63, 283-93.

20. Hameed N, Sreekumar PA, Francis B, Yang W, Thomas S (2007) Morphology, dynamic mechanical and thermal studies on poly(styrene-co-acrylonitrile) modified epoxy resin/glass fibre composites. Compos Appl Sci Manuf 38, 2422-32.

21. Mohanty S, Verma SK, Nayak SK (2006) Dynamic mechanical and thermal properties of MAPE treated jute/HDPE composites. Compos Sci Tech 66, 538-47.

22. Lopez MMA, Biagiotti J, Kenny JM (2002) Comparative study of the effects of different fibers on the processing and properties of ternary composites based on PP-EPDM blends. Polymer Compos 23, 779-89.

23. Lampman S, Bonnie Sanders B, Hrivnak N, Kinson J, Polakowski C (2003) Characterization and Failure Analysis of Plastics. $1 \mathrm{ed}$ : ASM International.

24. Syed MA, Akhtar S, Siddaramaiah Syed AA (2011) Studies on the physico-mechanical, thermal, and morphological behaviors of high density polyethylene/coleus spent green composites. J Appl Polymer Sci 119, 1889-95.

25. Hatkeyama T, Quinn FX (1994) Thermal Analysis, Fundamentals, and Applications to Polymer Science: Wiley: Cichester.

26. Sailaja RRN, Deepthi MV (2011) Mechanical and thermal properties of compatibilized composites of LDPE and esterified unbleached wood pulp. Polymer Compos 32, 199-209.

27. Jeevananda T, Siddaramaiah (2001) Thermal and morphological studies on ethylene-vinyl acetate copolymer-polyaniline blends. Thermochim Acta 376, 51-61. 